\title{
TÉCNICAS Y COMUNICACIÓN DURANTE LA INTERVENCIÓN SOCIAL
}

\section{TECHNIQUES AND COMMUNICATION DURING SOCIAL INTERVENTION}

Laura Ponce de León Romero y Antonio Ares Parra

Profesora Doctora de Trabajo Social, UNED

Profesor Titular de Trabajo Social, Universidad Complutense de Madrid

\begin{abstract}
Resumen: En este artículo se exponen las principales técnicas con las que cuentan los profesionales para ejercer sus funciones durante la intervención social, donde la relación interpersonal entre el usuario y el profesional es imprescindible, y donde la comunicación ocupará un lugar destacado durante las entrevistas y la mediación. Se analizarán los aspectos necesarios para ofrecer garantías de éxito en la comunicación.
\end{abstract}

Palabras clave: Intervención Social, Técnicas, Comunicación, Emociones, Habilidades profesionales, Mediación, Entrevista.

Abstract: The aim of this paper is analyze main techniques during social intervention, where the interpersonal relationship between users and professionals is essential and where communication is a prominent part of interviews and mediation. Necessary aspects will be analyzed to offer guarantees of success in communication.

Key Words: Social Intervention, Techniques, Communication, Emotion, Professional Skills, Mediation, Interview.

\section{Introducción}

Los profesionales encargados de llevar a cabo una intervención social tienen que usar una serie de técnicas para lograr sus fines u objetivos. A continuación se describen las más importantes vinculadas directamente con la comunicación, que serían dos fundamentalmente: la entrevista y la mediación. 
La entrevista es definida "como el encuentro hablado entre dos personas que conforman interacciones tanto verbales como no verbales" (Pope, 1979: 67), o como un diálogo constructivo, que tiene unos objetivos revisables a lo largo de un proceso reflexivo, pero sobre todo, participativo, convirtiéndose en un constructor de comunicación que debe ir más allá de la mera recogida de datos (Ariño, 2008: 25). Representa la relación interpersonal de apoyo profesional, a través de la cual, se intercambia información con el usuario, constituyéndose como el elemento básico para garantizar un cambio en la situación problemática del caso.

La mediación se suele utilizar cuando las partes implicadas no se ven capacitadas por sí mismas para superar un conflicto. La mediación se sustenta en supuestos que le dotan de especificidad dentro del marco general de la resolución de conflictos: confidencialidad, neutralidad, colaboración, voluntariedad y visión de futuro (De Diego y Guillén, 2010).

Resulta muy complicado conocer los innumerables campos donde se puede aplicar la mediación como forma de resolver los conflictos que se originan en la vida cotidiana. El conflicto ha acompañado a las relaciones humanas desde que éstas existen ya que en todas las relaciones se producen tensiones, porque en cualquier momento los intereses pueden confrontarse.

Otras definiciones pueden dotar al concepto de la mediación un valor terapéutico, entendiéndola como una herramienta o técnica cuya aplicación permite la resolución de conflictos de una manera pacífica y consensuada, mediante la colaboración neutral e imparcial del profesional que contribuye a la creación de un espacio de diálogo y comunicación adecuada capaz de facilitar la consecución de acuerdos (Fernández y Ponce de León, 2016: 92).

Para realizar la intervención social los profesionales además de saber utilizar las técnicas anteriormente mencionadas, deberían disponer de tres habilidades básicas (Fernández y Ponce de León, 2012): la empática o saber ponerse en el lugar del otro, saber cuidarse a uno mismo y sobrellevar situaciones de estrés pues a veces pueden afectarnos los casos emocionalmente, y por último ser buen comunicador. En esta última habilidad nos centraremos a continuación. 


\section{La comunicación durante la intervención social}

En el proceso de intervención social, la comunicación que se establece entre profesional de apoyo y usuario resulta un elemento clave para la efectividad de la intervención y para generar empatía (Rogers, 1972).

El profesional no puede controlar el proceso de comunicación pero sí influir en él para facilitar el compromiso de acción del usuario, teniendo en cuenta las circunstancias concretas en que se produce que, normalmente, son situaciones de estrés y todo lo que conlleva de desorientación y bloqueo emocional, cognitivo y conductual.

La comunicación en el proceso de intervención tiene una finalidad clara: conseguir que las cosas se hagan. Conduce a la acción, al compromiso, al cambio de conducta que debe provocar una mejora en el bien-estar y bien-hacer del usuario.

Para conseguir efectividad en la intervención debemos ser conscientes de la necesidad de usar el método de comunicación adecuado. No se trata de tener buena voluntad y esperar a que los cambios se produzcan mágicamente, sino que se trata de tener el objetivo claro: qué lograr y el método para conseguirlo: cómo hacerlo.

La manera de preguntar o sondear, escuchar y responder son claves para la comunicación profesional de ayuda. Convencer desde la empatía y la persuasión es la forma de motivar a las personas a actuar sobre los aspectos modificables de la realidad. Dar reconocimiento es una buena forma de potenciar cambios de conducta. Carkhuff y Bereson (1977) exponen las características que un profesional debe reunir para fomentar un clima agradable de trabajo conjunto: honestidad, sinceridad, cordialidad, respeto, aceptación, comprensión y empatía. Según estos autores los profesionales deben respetar que cada persona es responsable de sí misma para organizar su destino, y por este motivo uno de los objetivos de la comunicación estará orientado a que la persona acepte y se responsabilice de su libertad de decisión para elaborar su propio cambio.

El cumplimiento de los requisitos anteriores facilita la relación desde un plano más psicológico, pero no debe olvidarse la importancia que tiene el medio ambiente físico donde se desarrolla la relación interpersonal, se debe cuidar con esmero el entorno en el que se produzca la comunicación: unas condiciones 
climáticas óptimas, suficiente luz, colores no agresivos, mobiliario adecuado, ausencia de ruidos e interrupciones, y facilitar la confidencialidad de los datos.

Garantizados estos aspectos psicológicos y físicos las acciones del profesional irán dirigidas a reforzar los siguientes aspectos personales (Bueno 2005: 87):

- Tranquilizar al usuario para que pueda reestablecer su equilibrio emocional. La información y el asesoramiento son dos de los elementos imprescindibles para su tranquilidad.

- Facilitarle la adquisición de habilidades y competencias relacionadas con la resolución de problemas, con la gestión de relaciones afectivas, con sus mecanismos de adaptación social, y con comportamientos relacionados con hábitos y procesos de conductas concretas.

- Estimular su recuperación, respetando las condiciones y posibilidades de la persona.

- Ofrecerle un espacio que facilite la intercomunicación. El proceso de apoyo profesional será una estrategia para enfrentarle a su realidad, eludiendo distorsiones que puedan alterar el cambio.

- Favorecer el equilibrio, la potencialización psicológica y social de la persona, restaurando y reforzando las habilidades que pueda afrontar con mayores garantías de éxito su situación problemática, evitando situaciones de dependencia o falta de autonomía personal.

Vamos a considerar la comunicación como una buena herramienta a cuidar en los procesos de intervención social. A ello dedicamos los párrafos que siguen. Hacemos las cosas lo mejor que podemos. Esa es nuestra fuerza. Podemos hacerlas mejor. Ese es nuestro aprendizaje.

\section{Características de la comunicación profesional: DECIR para que se HAGA}

Todos nosotros tenemos una gran experiencia en comunicarnos. Lo llevamos haciendo toda la vida, desde antes de nacer. Es imposible no comunicarse. También resulta imposible mantener comunicaciones "perfectas" porque son 
muchos los factores que influyen a la hora de realizar ese proceso de intercambio entre dos o más personas.

Podemos hablar por hablar o relacionarnos con otras personas para mantener contactos sociales, pasar el tiempo, divertirnos, conocerlas, influir en ellas, etc. También podemos realizar actividades productivas de cara a la realización de tareas. Nos relacionamos para hacer algo juntos o para indicar a otro que haga algo.

Cuando mantenemos relaciones profesionales, nos comunicamos para que hagamos algo con lo que decimos. Damos o nos dan instrucciones, órdenes, sugerencias, para que hagamos alguna actividad y para que realicemos esa actividad de una determinada manera, con un método, con una manera de hacer. Ese objetivo productivo, de transformar lo que decimos en lo que hacemos, configura y condiciona la forma de comunicarnos entre nosotros.

Cuando debamos decir algo a alguien para que lo haga la comunicación debe producirse desde la cercanía personal, sin necesidad de levantar la voz y cerca del lugar de la acción. No es necesario imaginar situaciones ficticias, alejadas de la realidad, si podemos ensayar la conducta en el lugar de la acción. Si es necesario acompañamos a nuestro interlocutor al escenario donde actuará para que se familiarice con lo que debe decir y hacer en un supuesto real. Por ejemplo, haciéndole indicaciones del tipo “¿Dónde te vas a sentar cuando hables con él/ella? ¿Qué es lo primero que le vas a decir? ¿Qué harás para no engancharte emocionalmente? ¿Qué crees que te dirá y qué vas a responder?

En la comunicación profesional, debemos solicitar feedback para saber si nos ha comprendido y, sobre todo, para conocer qué hará con lo que ha entendido. Expresiones como “¿me he explicado?” “me has comprendido?” “¿estás de acuerdo?” “lo harás?, etc., no sirven para nada porque sabemos de antemano lo que la persona va a responder: "si'". Lo que necesitamos es captar realmente su comprensión de lo que le hemos dicho. Por eso son más adecuadas las preguntas de tipo: ¿Qué es lo primero que vas a hacer? ¿Qué te parece clave en lo que hemos comentado? ¿Qué medios, ayudas, necesitarás para hacerlo? ¿En cuánto tiempo lo terminarás? ¿Cuándo me informarás al respecto? ¿Cómo sabrás que lo estás haciendo correctamente?

Cuando una persona realiza una acción se juega su autoestima. Por eso es muy importante supervisar el principio de la acción para que los primeros ensa- 
yos acierto-error puedan convertirse en aprendizaje y no en fracaso. Observamos que el feedback lo solicitamos preguntando. No tratamos de aconsejar ni controlar sino de potenciar y encauzar la actividad y responsabilizar al otro de su propia conducta.

El lenguaje profesional debe ser preciso. Debemos especificar lo que hay que hacer y preguntar al interlocutor cómo lo hará. El método, la forma de hacer, debe proponerlo, siempre que sea posible y hasta donde sea posible, el que ejecutará la acción. Lógicamente al dar una instrucción decimos al otro lo que debe hacer pero no cómo hacerlo.

El vocabulario utilizado debe ser el que nuestro interlocutor puede comprender con su nivel de formación y experiencia. Cuidado a las pedanterías de los expertos que utilizan un lenguaje críptico para lucir sus conocimientos.

Como la comunicación debe conducir a la acción al hablar debemos prever las consecuencias de lo que decimos. No hay lenguaje inocente. Lo que decimos ayuda o perjudica. Si algo sobra no lo digas. Al actuar debemos prever las consecuencias de nuestras acciones. No se trata de tener buena voluntad. Nuestra intención no cuenta. "El camino del infierno está empedrado de buenas intenciones”. Lo que sí cuenta es el impacto, las consecuencias que provocamos con lo que decimos. Una buena recomendación para no equivocarse o meter la pata mientras comunicamos, es ser prudentes y discretos, con todo lo que decimos y hacemos.

\section{Cómo persuadir: convencer no es argumentar sino desestabilizar creencias}

Todos tratamos de persuadir a alguien alguna vez. En las relaciones con otras personas tratamos de influir en ellas para que hagan algo que nos beneficie o agrade o para compartir un tiempo o una actividad. ¿Me prestas tu coche este fin de semana? ¿Me acompañas a ver una exposición?‘ ¿Vienes a bailar? ¿Nos juntamos para comer y charlar?

Queremos que la otra persona haga algo que sin nuestra invitación no haría. Buscamos la respuesta afirmativa. A veces, si se resiste, insistimos, damos alternativas, buscamos posibilidades para conseguir el acuerdo, la aceptación. En 
la comunicación profesional, desde el rol de consejero, trabajador social, coach, terapeuta, etc., tenemos que influir en la conducta de nuestro interlocutor para que haga algo nuevo o de otra manera o para que deje de hacer alguna cosa que le perjudica o le desagrada a él/ella o a otros. Lo primero que se suele plantear es el límite ético de la persuasión para distinguirla de la manipulación. Una forma sencilla de distinguir estas dos palabras, en la relación profesional, podría ser que mientras la manipulación favorece al que trata de influir, la persuasión favorece al influido/a. Otros aspectos importantes a tener en cuenta en la persuasión (Ares, 2013):

a) No se trata de persuadir buscando argumentos para quitar la razón al interlocutor. De esta forma sólo conseguiríamos polarizar la conversación y que terminaran argumentando uno a favor y otro en contra del tema que se aborda. El persuasor da argumentos a favor de sus propias ideas y el "persuadido" los va rechazando con frases como "sí, pero...” y proponiendo otra versión opuesta de la realidad examinada. Ninguno de los dos se atrevería a plantear toda la cuestión; sólo sacarían a relucir aquellos aspectos que reforzarían su postura inicial.

b) Se trata de acompañar al otro en su razonamiento desestabilizando sus creencias. Dejar que el "persuadido" hable y exponga sus razones y dificultades. Escucharle activamente. Comprenderle sin miedo. No darle argumentos en contra. Sí preguntarle para que el propio persuadido encuentre por sí sólo los argumentos "en contra" de su postura inicial, es decir, encuentre excepciones a su propio discurso. Aspectos que no haya tenido en cuenta en su postura inicial. Las creencias son generalidades que aceptan excepciones. Ahí debemos centrarnos para desestabilizar la creencia que impide el cambio de conducta.

c) Ayudarle a plantearse cambios en su conducta para encontrar formas más sanas, con menos costes materiales o emocionales, para alcanzar sus objetivos. A qué se compromete el "persuadido", qué está dispuesto a hacer y cómo lo hará en su situación, posibilidades, tiempo disponible, etc.

La persuasión es básica en la relación de ayuda para comprometer al otro en un cambio de conducta que le resulte beneficioso para alcanzar sus objetivos vitales. 


\section{La comunicación como relación interpersonal: Preguntar-Escuchar-Responder}

En la comunicación profesional, comunicación profesional que se establece entre un usuario o cliente, en muchas ocasiones debemos informarnos de lo que le sucede o necesita. Para captar bien la situación debemos obtener datos necesarios para poder hacernos una composición de lugar, para comprender la situación y poder intervenir en ella. Es importante, igualmente, que nuestro interlocutor se sienta comprendido. Que note que empatizamos con él/ella y nos hacemos cargo de sus situación. Para ello es importante que se sienta escuchado.

El usuario de un servicio no cuenta su historia a un profesional sólo para que le escuche, sino para que comprenda su situación y, sobre todo, para que haga algo. ¿Qué puede hacer el profesional que sirva de ayuda al que demanda la escucha? Estos aspectos que acabamos de esbozar sobre la comunicación profesional: obtener información, comprenderla y reaccionar, son aspectos que vamos a desarrollar a continuación.

Para obtener información debemos saber cómo hacer las preguntas que nos van a permitir recoger la información que vamos a precisar para nuestros fines profesionales, pues la finalidad de preguntar es obtener datos verdaderos y valiosos. Si las respuestas no aportan nada la pregunta sobra. Por ejemplo, decirle a alguien durante una entrevista en que está solicitando una ayuda económica: ¡es usted una persona despilfarradora o controla usted bien el dinero? La respuesta sería obvia y por tanto la pregunta sobraría, además el usuario podría sentirse juzgado, o podría pensar que tratamos de etiquetarlo como una persona despilfarradora. En ambos casos una mala pregunta podría poner en peligro el trabajo previo de empatía y calidez generado, por este motivo se deben cuidar las preguntas que hacemos, cómo las hacemos y valorar el momento en el que las tendríamos que hacer.

A veces sondeamos porque no podemos preguntar directamente. No es lo mismo preguntar que sondear. $\mathrm{Al}$ sondear conversamos sobre otros temas, más o menos tangenciales al que nos interesa y de las opiniones de nuestro interlocutor vamos deduciendo la información que nos interesa obtener.

Preguntar tampoco es interrogar. No podemos hacer durante una entrevista tantas preguntas que terminemos agobiando a nuestro interlocutor. Debemos pre- 
guntar poco y pudiendo relacionar las diferentes respuestas hasta obtener un diagnóstico de la situación. No se trata de preguntar por preguntar o por cotillear. Debemos centrarnos en el tema sobre el que queremos recibir información sin desviarnos hacia aspectos no relevantes. Tener presente en nuestra cabeza los objetivos que perseguimos nos ayudará a centrarnos en aquello que es interesante.

Tradicionalmente se suele distinguir entre preguntas abiertas y cerradas. Abiertas son las que se responden con un relato. Las cerradas son las que se responde con un monosílabo o una sola palabra: Sí-No, Verdadero-Falso, Verde, París, etc. Para obtener mayor información debemos decir expresiones como: Explícame, cuéntame, Qué relación hay entre esto y aquello. También podemos usar: Cómo, Cuándo, Dónde, Por qué, Para qué, etc.

Cuando hago preguntas cerradas al principio de una conversación no trato de que el otro me lo cuente sino que estoy interesado en adivinar, en construir yo la historia, que desde ese momento es mi historia, desde mi punto de vista, pero no estoy escuchando la que me cuenta el otro. Si me dicen "suena una campana” tal vez yo ya estoy imaginando una iglesia pero la campana puede sonar en un cuartel, un barco o un colegio para llamar a clase. No anticipemos acontecimientos al preguntar; los acontecimientos los descubriremos al escuchar.

Así que para obtener información, preguntamos, sondeamos, interrogamos, averiguamos, captamos, deducimos, etc. Muchas son las maneras de facilitar que el otro nos aporte información relevante para hacer un diagnóstico de la situación sobre la que luego deberemos proponer intervenciones.

Pero no solamente debemos saber preguntar..., no menos importante es saber escuchar. La mayoría de las personas suponemos que sabemos escuchar porque oímos normalmente y eso es fuente de confusión: oír no es lo mismo que escuchar. Oímos con los oídos y escuchamos con el cerebro. La escucha requiere atención y comprensión del mensaje. En una conversación, oír lo que me dicen y comprender el mensaje requieren conocer mis límites de comprensión y los juicios que hago de lo que capto. Para comprender preciso aceptar sin juzgar el pensamiento del otro sin interrumpirle, ni desviarle ni adelantarme a lo que escucho.

La escucha pasiva consiste en saber guardar silencio mientras la otra persona nos está comunicando sus ideas, sentimientos, etc. Es un buen instrumento 
para hacer que las personas hablen y yo me entere. Se suelen utilizar monosílabos para romper el silencio de vez en cuando para que la otra persona comprenda que la estamos escuchando. Acompañamos nuestros mensajes verbales de gestos no verbales que indican al otro que prestamos atención a lo que dice. Mostramos al otro nuestra disposición e interés por escucharle mediante expresiones como «explícame más eso»o «¿qué quieres decir?». Aunque la escucha pasiva ayuda a la persona a empezar a hablar, ninguna de esas técnicas asegura al emisor que la persona que escucha entiende realmente.

Por otro lado la escucha activa consiste en resumir, sintetizar y comprender las ideas centrales, los sentimientos del otro, pero sin añadir nuestro punto de vista personal. El protagonista es el que habla. Es una técnica útil cuando nos enfrentamos a un conflicto donde se añaden factores emocionales a los racionales, porque confirmamos al que habla que hemos comprendido lo que quiso decir. Al aplicar este procedimiento, la persona que escucha lo que hace es reformular con sus propias palabras la impresión que ha recibido de lo que expresa el emisor. No se trata simplemente de sintetizar lo que se ha oído del mensaje racional sino también que se comprende el mensaje emocional que nos llega. Hay tres formas de utilizar la escucha activa (Ares, 2015):

- Eco: repetición textual de lo dicho por el otro.

- Reformulación: expresar con mis palabras lo que he captado del mensaje racional y emocional.

- Reflejo de sentimientos: expresar solamente el sentimiento que he percibido en el otro.

Preguntar y escuchar me ayuda a COMPRENDER. Dar información me ayuda a SER COMPRENDIDO. Procurar comprender al otro requiere consideración; procurar ser comprendido requiere coraje.

\section{Cómo dar Reconocimiento para potenciar cambios de conducta}

En algunas ocasiones el profesional podría utilizar el reconocimiento durante la comunicación con el usuario para aumentar su motivación y hacia la consecución de un cambio. ¿Qué significado tiene el verbo reconocer? Según la 
Real Academia de la Lengua Española (RAE) es sinónimo de observación, identificación, comprobación, recuerdo, agradecimiento. Reconocer es mirar, ver, considerar, aceptar, recordar. Lo opuesto a reconocer sería rechazar. El reconocimiento que reciben las personas hace que adquieran visibilidad, se hagan notar, existan, se les tenga en cuenta.

En el marco de la intervención social reconocer al usuario es cumplir con algunos de los principios éticos de la profesión, entre ellos la aceptación de cada persona con todas sus capacidades y potencialidades. No se trata de dar dinero o premios de cualquier índole. Se trata de hacerles saber que existen, que se les tiene en cuenta, que son importantes, que aportan valor, y que por supuesto no son un número más de expediente. Las personas necesitamos que nos saluden ("buenos días"), nos respeten ("por favor") y nos agradezcan ("gracias”). Reconocer al otro significa (Ares, 2015):

- Escuchar con atención lo que la persona expresa. No sólo oir, sino comprender qué es lo que piensa y siente, tanto si estamos de acuerdo como si no lo estamos y hacerle saber que lo hemos comprendido. Eso no quiere decir que estemos de acuerdo, sólo que sabemos lo que expresa.

- Facilitar que aprenda: protegiéndole para que no asuma riesgos innecesarios, potenciando que pueda experimentar y permitiendo que adquiera responsabilidad y autocontrol de las tareas que realiza.

- Mostrarse disponible para explicar lo que hay que hacer y aceptar las aportaciones del interlocutor sobre cómo hacer las actividades.

- Respetar el tiempo de los demás, sus necesidades y deseos. Singularizar a cada persona. Nuestras necesidades y deseos son diferentes. Cada persona es diferente y única. Debemos reconocer en el otro sus necesidades, peculiaridades, capacidades y potencial.

Algunos prejuicios dificultan el que demos reconocimiento: nos falta costumbre ("no me sale con naturalidad"), tememos ser malinterpretados ("me van a pedir algo a cambio"), consideramos que no sirve para nada ("lo único que tiene valor es el dinero") o que es lo contratado y se le paga por ello ("hacerlo bien es su obligación"). 
El reconocimiento es una forma de elevar la autoestima, y afecta directamente a nuestra conducta. Basamos nuestra valía en las experiencias que hemos ido acumulando a lo largo de toda nuestra vida. La realidad nos ha ido informando sobre nuestros éxitos y fracaso, nuestras habilidades y torpezas, nuestras dificultades y facilidades. Aceptar toda esta información a veces puede resultar complicado, pues todos estos datos acumulados puede distorsionarse con nuestras propias apreciaciones o con las de los demás. Lo que hemos comprobado por nosotros mismos sobre nuestro buen o mal hacer y lo que nos han alabado o reprochado otras personas sobre nuestras capacidades técnicas o de relación han ido configurando nuestra autoevaluación, tanto en positivo como en negativo.

Además, la imagen que tenemos de nosotros mismos no permanece estable. Depende del éxito o fracaso ante cada acontecimiento cotidiano. ¿Me sigo considerando buen vendedor el día que no consigo una venta? ¿Cada vez que pierdo una venta siento que soy un mal profesional? ¿La percepción de nuestra autoestima disminuye o aumenta con facilidad, al hilo de los éxitos y fracasos?

Debemos considerar la importancia de tener una sana o buena autoestima. No se trata de que sea alta, y menos "desmadrada", sino positiva y realista. No necesito ser perfecto, sólo ser capaz de hacer lo que hago muy bien; asumo mis errores y limitaciones; no sirvo para todo de igual modo; me siento bien a pesar de ello. Se trata de aceptarnos más que de considerarnos "perfectos". Aceptarnos como somos y creer en nuestra capacidad de aprendizaje y adaptación nos ayudará a entender que la realidad que vivimos se construye día a día, y que ésta depende de nosotros mismos, no de los demás. Eso nos hará responsabilizarnos de nuestros cambios y elegir otros nuevos caminos, si los que hemos tomados no han sido del todo buenos.

Las personas con baja autoestima adoptan una actitud excesivamente quejumbrosa, crítica, insegura, triste, perfeccionista, agresiva o derrotista. Suelen tener una necesidad exagerada de aprobación, de llamar la atención, de ganar. Se muestran poco sociables y con temor excesivo a equivocarse.

Las personas con sana autoestima muestran confianza en sí mismos, autocontrol de sus impulsos, flexibilidad, autonomía, responsabilidad, iniciativa y creatividad. Conocen sus habilidades y carencias, se esfuerzan y se comprometen. 
La autoestima se apoya en la conciencia del propio valor, la percepción de la propia capacidad y la confianza en sí mismo. Todos estos elementos se deben trabajar durante la intervención social, si queremos empoderar a la persona a partir de un cambio. Pero no debemos sobrevalorar las capacidades del usuario para así aumentar su reconocimiento y elevar su autoestima. Tendremos que ser coherentes con nuestros comentarios, que deberían ajustarse a la realidad del caso.

Lo interesante es que una sana autoestima favorece los éxitos y ayuda a soportar los fracasos. No atribuye el éxito a la suerte ni el fracaso a la mala suerte. Aceptar retos y alcanzar metas dependen de factores controlables desde la propia responsabilidad. Se deben a sus capacidades y al esfuerzo realizado para planificar y realizar el trabajo que le lleva a alcanzar las metas propuestas.

El reconocimiento afecta a la autoestima. Reconocer a una persona es tenerle en cuenta, considerarla visible y audible, aceptar su derecho a "ser" y "estar", no sólo a "hacer". No se trata, inicialmente, de valorar su conducta sino de constatar y aceptar su presencia. Cuando una persona es reconocida de manera adecuada aumenta su autoestima porque se siente aceptada como persona. Sabe que puede opinar, contribuir, aportar, cuestionar, resolver. Conoce dónde aporta valor a los procesos de productividad personal o familiar, el lugar que ocupa, y la importancia que tiene para los demás.

El cambio de conducta que se requiere en la actualidad no consiste tanto en la corrección puntual de errores, sino en planificar la mejora permanente de todos y cada uno, no sólo corrigiendo sus acciones disfuncionales e inadecuadas sino, sobre todo, desarrollando sus capacidades, estando abiertos a cambiar lo que funciona, introduciendo innovación, asumiendo riesgos y explorando oportunidades.

Decirle a otro que lo hace mal servirá como desahogo propio o sofoco ajeno pero poco ayudará a la mejora de su conducta. Lo importante no es decirle a otro qué hace mal sino cómo hacerlo bien y con qué ideas, medios, tiempo, etc. cuenta para lograr su objetivo. Desde el punto de vista motivacional, conseguimos influir adecuadamente en otro cuando constatamos que:

- mejora la relación entre el que realiza la conducta y el que la supervisa.

- mejora la realización de la tarea a través de las indicaciones que se incorporan y a través de los aprendizajes que se van adquiriendo al realizarla. 
Lo correcto en las indicaciones que pretenden cambio de conducta ajena sería la abundancia de reconocimiento concreto y positivo de lo que la persona "hace" y el uso discreto de crítica sobre lo que se hace mal siempre que se indiquen caminos de corrección y que se perciban las posibilidades de cambio y mejora posible en la persona implicada y con el tiempo, capacidad y recursos de que disponga.

La ausencia de Reconocimiento es el peor Reconocimiento. Enviamos un mensaje de descalificación; le manifestamos al otro que no existe, que es transparente, que pasa desapercibido, que no cuenta. El reconocimiento debe ser concreto, claro, directo, verdadero, honesto. Dado sobre las conductas que se observan más que sobre las que se intuyen. Cercano en el tiempo a la acción que se considera. Facilitando la aportación de conocimientos y opiniones sobre el modo de hacer la tarea.

Debemos confiar en las capacidades de las personas para aprender a través de la puesta en práctica de las ideas. Trabajamos con las cualidades no con los defectos de cada uno. Es importante señalar que el reconocimiento se realiza sin promesas de recompensas de ningún tipo.

\section{Canalización emocional: emociones auténticas y distorsionadas}

La conciencia emocional nos informa de lo que sentimos y de los vínculos que se establecen entre nuestros pensamientos, sentimientos, lenguaje y acciones, los cuatro componentes de la conducta.

En las acciones manifestamos nuestros estados emocionales; por tanto, las emociones afectan a los resultados y consecuencias que provocamos con nuestra conducta. El reto de aprender a sentir de manera más saludable nos abre muchas posibilidades de desarrollo vital ya que nos permite relacionarnos "de otra manera”: más placentera, con menos costes para la relación, más eficaz para conseguir nuestros objetivos.

Las emociones auténticas son las emociones básicas. Entendemos como distorsionadas algunas reacciones emocionales que se aprenden en las relaciones sociales infantiles y que no expresan, de manera genuina, nuestras necesidades biológicas. 
Al hacer esta distinción entre emociones auténticas y distorsionadas no pretendemos introducir una visión moral para separar lo bueno de lo malo sino sólo hacer descripciones de fenómenos que observamos y que nos pueden facilitar nuestros cambios de conducta.

Respetando las observaciones sobre el nivel de conocimiento actual sobre la materia, nos arriesgamos a explicar las emociones con genuina intención pedagógica: comprender nuestra capacidad instintiva para sobrevivir, desarrollarnos y relacionarnos. No todos los autores están de acuerdo en lo que nosotros designamos como emociones. Algunas consideradas tales faltan (asco, sorpresa, etc.) y alguna sobra (amor). No pretendemos entrar en precisiones propias de investigadores expertos en la materia. Las emociones auténticas se caracterizan por ser (Ares, 2015):

- Breves: se manifiestan ante situaciones concretas; cuando cambia la situación, cambia la emoción.

- Intensas: aparecen con fuerza y se van debilitando.

- Adecuadas: las esperamos como sentimiento normal ante la situación que se presenta.

- Con aceptación social: las demás personas suelen entender ese estado de ánimo y ayudan a su canalización.

Al hablar de emociones auténticas abrimos, por contraposición, la posibilidad de hablar de las que no lo son. A éstas les llamamos distorsionadas o sustitutivas. Se producen como reacciones aprendidas socialmente que no son adecuadas por su naturaleza, intensidad y duración a la respuesta que requiere la situación vivida y por la que se paga un coste emocional, corporal o social excesivamente elevado. Sustituyen a las auténticas que deberían aparecer. Las emociones distorsionadas:

- Sustituyen a las emociones auténticas que tenemos dificultad para sentir o expresar.

- Reprimen la manifestación genuina de esa emoción en particular y la trasladan a otro canal emocional. 
- Se prolongan en el tiempo como emoción crónica.

- No corresponden a la demanda de la situación.

- La persona no se responsabiliza por lo que piensa, siente o hace; considera que está obligado a sentir así en función de su pensamiento y que no existen otras posibilidades de expresión de su sentir.

Ejemplos de emociones distorsionadas pueden ser: culpa, resentimiento, ansiedad, agitación, envidia... Contar chistes en un entierro, reírse cuando una persona tropieza y se cae, pegar puñetazos a una puerta, bloquearse antes de realizar una presentación en público, deprimirse por no lograr los resultados esperados, aislarse de otros por miedo a meter la pata, y otras muchas situaciones cotidianas, nos muestran como normales, por usuales, reacciones emocionales que no indican el mejor grado emocional en sus autores. Seguir enfadado por la bronca con mi jefe de hace meses, triste por la muerte de mi perro años después de su fallecimiento, entusiasmado con la promesa de promoción para el año próximo, enamorado de la mujer que me ha rechazado varias veces, asustado por el rumor de que la empresa no va bien, etc. Son ejemplos de este tipo de reacción emocional inadecuada.

A pesar de los ejemplos expuestos, reconocemos que distinguir la reacción emocional adecuada de la inadecuada es un tema bastante complicado y en el que es difícil encontrar acuerdo unánime. Sin embargo, hacemos esta propuesta de distinción porque creemos que funcional y éticamente es bueno educar la emoción. Parece mejor apiadarse del otro que reírse de él cuando tropieza y se cae.

Las emociones auténticas son universales y "van asociadas a diferentes tendencias de acción, probablemente no aprendidas, destinadas a hacer frente al suceso desencadenante de la emoción” (Aguado, 2010: 39). Su expresión suele ser intensa, breve, relacionada con el contexto en el que se reacciona y cercana en el tiempo al hecho que la origina. Llorar en un entierro, asustarse al caerse por una escalera, enfadarse con alguien que nos acaba de ofender al no respetar el turno que le correspondía, alegrarse cuando me cuentan un chiste gracioso, abrazar a un compañero que hacía tiempo que no coincidíamos, son ejemplos de expresiones emocionales auténticas. Las emociones que acabamos de exponer son las que nos permiten: 
- Sobrevivir: atacando con fuerza, huyendo con rapidez, inmovilizándose, pasando desapercibido.

- Desarrollarnos: jugando, divirtiéndonos, practicando.

- Relacionarnos: reproduciéndonos'para mantener la especie, colaborando con otros para protegernos.

Nuestro cerebro aprendió en nuestros antepasados y está preparado para reaccionar ante crisis agudas e imprevistas y reaccionar de manera intensa, breve y rápida. La nueva selva, la del asfalto, nos pide estar reaccionando de manera permanente y sosegada, para lo cual nuestro sistema límbico no está muy preparado.

Cuando mi jefe me regaña me pueden entrar ganas de atacar o de huir pero debo aguantarme calladito y quietecito. Claro, luego el sistema neurovegetativo me pasa la correspondiente factura a esta incongruencia entre mi sentir y mi actuación y se lo cobra en dolor de cabeza o de espalda, tensión arterial, ardor de estómago, etc.

Distorsionamos nuestras emociones auténticas con la esperanza de adaptarnos a las situaciones que se nos presentan. Aprendimos en nuestra infancia a reaccionar, básicamente por amor o miedo, tomando decisiones prematuras, y grabando en nosotros la costumbre de reaccionar como creíamos que era lo mejor, lo más adecuado, lo posible en esas circunstancias. Nuestra intención era saludable: queríamos sobrevivir, desarrollarnos, protegernos, pero esas reacciones que nos sirvieron en un momento dado puede que en el presente nos estén dificultando la expresión de lo que realmente sentimos y tenemos derecho a expresar de manera adecuada. No hemos aprendido todavía la inteligencia emocional suficiente para afrontar las nuevas situaciones.

Vamos a exponer cómo satisfacer, en nuestra realidad actual, esas necesidades básicas de expresión, nuestras emociones:

- de supervivencia: rabia para atacar, miedo para escapar, tristeza para adaptarnos.

- de desarrollo: Alegría para aprender y disfrutar.

- de relación:Amor (afecto) para colaborar con otros y ser amables (dignos de amor). 
Sin necesidad de distorsionar o reprimir nuestros sentimientos auténticos como tributo a nuestros primeros aprendizajes, que limitaron nuestras opciones a una costumbre adquirida. Ahora, en el momento presente, podemos permitirnos nuevas opciones de conducta con las que expresemos nuestras emociones de manera más auténtica y satisfactoria. Si canalizamos de manera adecuada nuestras emociones conseguiremos mayor confort para nosotros mismos y relaciones más auténticas y satisfactorias.

Durante la intervención social y en la relación interpersonal que se establece entre usuario y profesional todos estos aspectos emocionales estarán influyendo en el proceso de comunicación, que se produce durante las entrevistas y los procesos de mediación, para la resolución de conflictos y problemas.

\section{Bibliografía}

AGUADO, L. (2010). Emoción, afecto y motivación. Madrid: Alianza editorial.

ARES PARRA, A. (2013). Importancia del Reconocimiento para fomentar el buen desempeño laboral. Revista de Análisis Transaccional y Psicología Humanista 69, 192-202.

ARES PARRA, A. (2015). Las emociones en el ámbito laboral. Estrategias para la promoción de comportamientos saludables. En R. De Diego (Coord.), Empleo, personas y organizaciones. Cambios y transformaciones (pp.133-140). Madrid: Pirámide.

ARIÑO, M. (2008). La entrevista en Trabajo Social. En C. Guinot (Coord.), Métodos, Técnicas y documentos utilizados en Trabajo Social (pp. 69-76). Bilbao: Deusto Publicaciones.

BUENO, J.R. (2005). El proceso de ayuda en la intervención psicosocial. Madrid: Editorial Popular. CARKHUFF, R. R., y B. C., BERENSON. (1977). Beyond Counseling and Therapy. Nueva York: Holt, Rinehart and Winston.

DE DIEGO, R., y GUILLÉN, C. (2009). Mediación: Procesos, tácticas y técnicas. Madrid: Ediciones Pirámides.

FERNÁNDEZ GARCÍA, T., y PONCE DE LEÓN, L. (2012). Trabajo Social Individualizado: Metodologías de intervención. Madrid: Ediciones Académicas.

FERNÁNDEZ GARCÍA, T., y PONCE DE LEÓN, L. (2016). Elaboración, gestión y evaluación de proyectos sociales. Madrid: Pirámide.

POPE, B. (1979). The mental health interview: research and application. New York: Pergamon.

ROGERS, K. (1972). Terapia centrada en el cliente. Buenos Aires: Paidós. 